\title{
Nature of Regulatory T Cells in the Context of Allergic Disease
}

\author{
Cevdet Ozdemir, MD, Mübeccel Akdis, MD, PhD, and Cezmi A. Akdis, MD
}

\begin{abstract}
Allergen-specific immunotherapy (SIT) is the cornerstone of the management of allergic diseases, which targets modification of the immunologic response, along with environmental allergen avoidance and pharmacotherapy. SIT is associated with improved tolerance to allergen challenge, with a decrease in immediate-phase and late-phase allergic inflammation. SIT has the potential to prevent development of new sensitizations and progression of allergic rhinitis to asthma. It has a role in cellular and humoral responses in a modified pattern. The ratio of $\mathrm{T}$ helper (Th)1 cytokines to Th2 cytokines is increased following SIT, and functional regulatory $T$ cells are induced. Interleukin-10 production by monocytes, macrophages, and $B$ and $T$ cells is increased, as well as expression of transforming growth factor $\beta$. SIT is associated with increases in allergen-specific antibodies in IgA, IgG1, and IgG4 isotypes. These blocking-type immunoglobulins, particularly IgG4, may compete with IgE binding to allergen, decreasing the allergen presentation with the high- and low-affinity receptors for IgE (FceRI and FceRII, respectively). Additionally, SIT reduces the number of mast cells and eosinophils in the target tissues and release of mediators from these cells.
\end{abstract}

Key words: dendritic cells, mucosal tolerance, regulatory T cells, allergen-specific immunotherapy

$T$ he allergic immune response is directed against various environmental allergens and manifests clinically as allergic rhinitis, allergic asthma, food allergy, allergic skin inflammation, ocular allergy, and/or anaphylaxis. Contact of an allergen with the immune system starts with handling of it by the antigen-presenting cells, mainly dendritic cells (DCs), which process antigenic material and present it on its surface to other cells of the immune system, especially to $\mathrm{CD}^{+} \mathrm{T}$ helper (Th) 2 cells. This results in Th2-type cytokine production (interleukin [IL]4, IL-13), which causes class switching of B cells for production of IgE. Allergen-specific IgE antibodies bind to high-affinity Fc\&RI receptors that are expressed on mast cells and basophils. On reexposure to the same offending allergen, interaction of allergen with allergen-specific $\operatorname{IgE}$

Cevdet Ozdemir: Division of Pediatric Allergy and Immunology, Istanbul, Turkey; Mübeccel Akdis and Cezmi A. Akdis: Swiss Institute of Allergy and Asthma Research, Davos, Switzerland.

The authors' laboratory is funded by the Swiss National Science Foundation (grants no. SNF-32-112306/1, 32-118226) and the Global Allergy and Asthma European Network.

Correspondence to: Cezmi A. Akdis, MD, Swiss Institute of Allergy and Asthma Research, Obere Strasse 22, CH-7270 Davos, Switzerland; email:akdisac@siaf.unizh.ch.

DOI 10.2310/7480.2008.00015 results in degranulation of preformed granules in mast cells. In addition to the release of histamine and proteases, the synthesis and release of newly generated lipid-derived mediators, such as leukotrienes and cytokines, responsible for the symptoms and signs of allergic disorders occur. ${ }^{1-3}$ The late-phase response appears during the 6- to 12-hour period after allergen exposure and is a cell-driven process with infiltration of eosinophils, neutrophils, basophils, T lymphocytes, and macrophages, which release additional inflammatory mediators and cytokines, perpetuating the proinflammatory response. This late-phase response is thought to be responsible for the persistent, chronic signs and symptoms of allergic diseases. Continued allergen exposure often establishes a state of chronic symptomatic inflammation. ${ }^{4,5}$

Treatment strategies such as antihistamines, antileukotrienes, $\beta_{2}$-adrenergic receptor agonists, and corticosteroids aiming at suppression of mediators and immune cells can be used to control the symptoms and progression of allergic diseases; however, cessation of these treatments may eventually lead to the relapse of the disease. ${ }^{6}$ Allergenspecific immunotherapy (SIT) represents the only curative and unique method of treatment for allergic disorders, specifically restoring normal immunity against previously disease-causing allergens and therefore offering a longlasting solution. ${ }^{6-14}$ 
The mechanisms by which SIT has its effects include the very early desensitization effect. The regulation of Tcell responses by generation of $\mathrm{T}$ regulatory (Treg) cells induces peripheral T-cell tolerance. Modulation of B-cell interactions results in alterations in allergen-specific $\operatorname{IgE}$ and IgG subtype synthesis. Also, suppression of effector cells (eosinophils, basophils, and mast cells) and their inflammatory responses occurs (Figure 1). ${ }^{1,3,6,15-18}$ For an efficient immunotherapy course, well-standardized native proteins or recombinant allergens should be used to induce tolerance in allergen-specific $\mathrm{T}$ cells. For accurate results, SIT is expected to suppress IgE production and type I skin test reactivity in accordance with promoting IgG4 and IgA types of antibody production that can block the responsiveness of IgE for allergens. For a safe and efficient SIT, it is a requisite to develop routes with ease of applicability that will have persistent clinical effectiveness that can be built within a short duration of therapy time. ${ }^{1}$

\section{Early and Late Effects of SIT on Mast Cells, Basophils, and Eosinophils}

SIT has early and late impacts on major cells of allergic inflammation. Rapid clinical tolerance induction can be seen in rush and ultrarush bee venom immunotherapy (VIT) protocols over several hours, which supports the effect of SIT on early desensitization. It has been demonstrated that an absolute amount of histamine released in response to stimulation was decreased after major bee venom allergen stimulations. Moreover, a significant reduction in leukotriene $\mathrm{C} 4$ production after VIT in samples stimulated with that specific allergen was reported. ${ }^{19}$ Additionally, suppression of basophil IL-4 and IL-13 during early phases of rush immunotherapy has been demonstrated. ${ }^{20,21}$

SIT modifies the number and the function of effector cells that mediate the allergic response. ${ }^{3,22}$ For example, the numbers of Th2 cells and eosinophils are reduced at
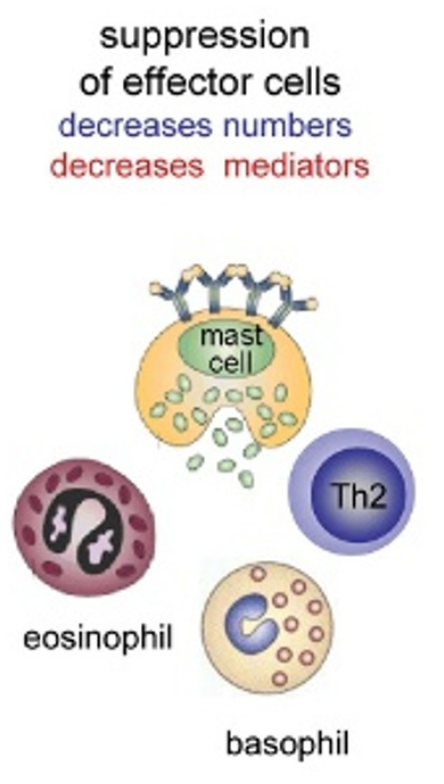

very early desensitization effect

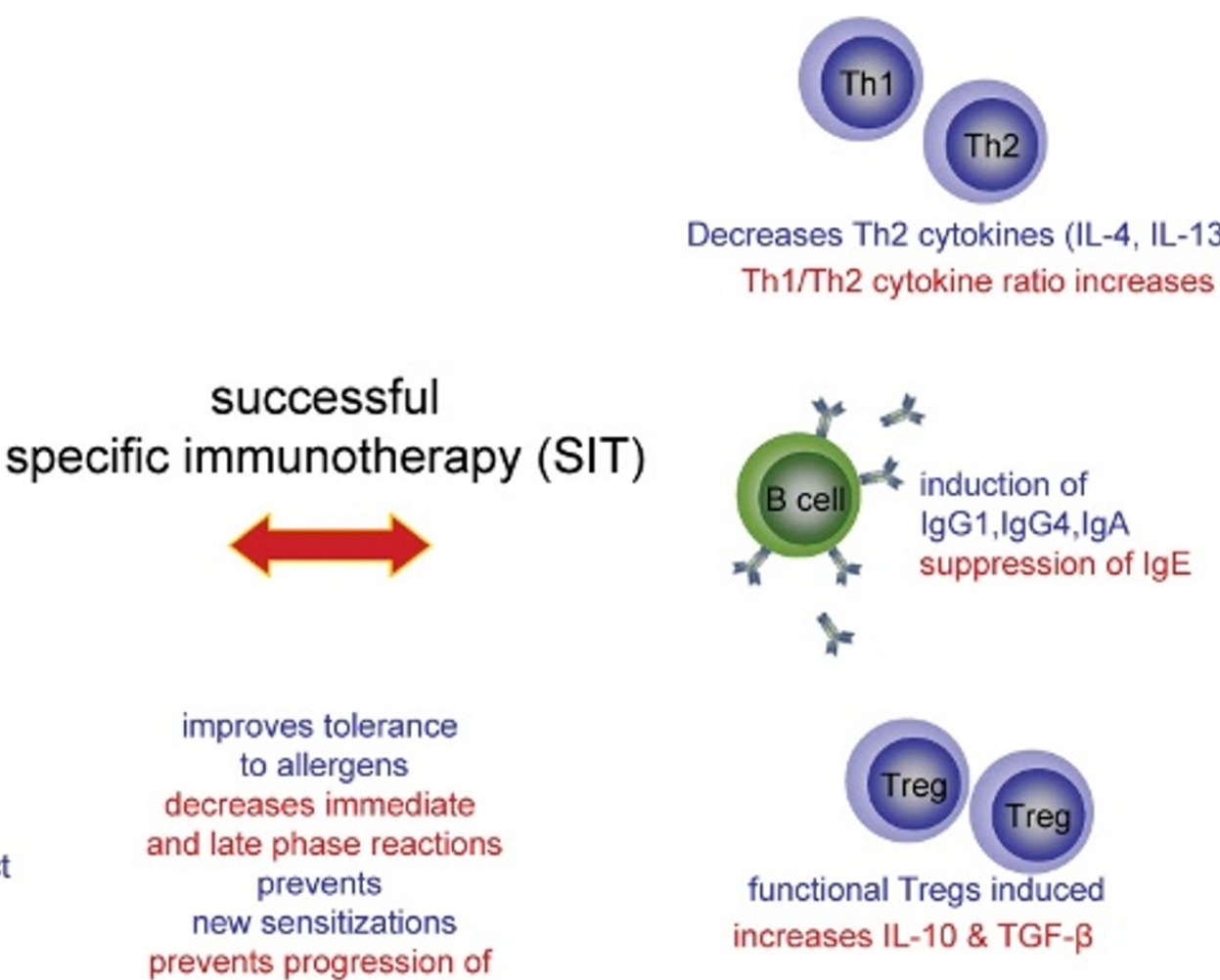

allergic rhinitis to asthma

Figure 1. Allergen-specific immunotherapy (SIT) is associated with improved tolerance to allergen challenge, with a decrease in immediate-phase and late-phase allergic inflammation. SIT also reduces the number of effector cells and release of their mediators in the target tissues. It has a role in cellular and humoral responses. T helper (Th)2 cytokines are decreased, and functional regulatory T cells (Tregs) are induced. Interleukin (IL)-10 production by monocytes, macrophages, $\mathrm{B}$ cells, and T cells is increased, as well as expression of transforming growth factor $\beta$ (TGF- $\beta$ ). SIT is associated with increases in allergen-specific antibodies in IgA, IgG1, and IgG4 isotypes. SIT also prevents development of new sensitizations and progression of allergic rhinitis to asthma. 
sites of allergen challenge following SIT. ${ }^{23,24}$ Furthermore, SIT reduces the seasonal increases in the number of basophils and eosinophils ${ }^{25,26}$ in the mucosa, as well as the number of mast cells in the $\operatorname{skin}^{27}$ and the IgE-mediated release of histamine by basophils. ${ }^{3,28}$ Also, a significant decrease in nasal eosinophils after 2 years of sublingual immunotherapy was shown. ${ }^{29}$

\section{Effects of SIT on Dendritic Cells}

To understand the mechanisms of action of SIT, some cardinal steps should be explained. The first question is which type of cells will be the pioneers to present the allergen to $\mathrm{T}$ cells? Will it be plasmacytoid dendritic cells (pDCs), myeloid dendritic cells (mDCs), immature DCs, or Langerhans cells (LCs)? This decision is normally made by the type of adjuvant and is an essential issue for the future of SIT vaccine development.

Tolerance is the usual outcome of inhalation of harmless antigens. Both mDCs and pDCs take up inhaled antigen in the lung and present it in an immunogenic or tolerogenic form into the draining lymph nodes. ${ }^{30,31}$ The essential role of lung pDCs in preventing the cardinal features of asthma has been demonstrated by experiments depleting pDCs, which lead to IgE sensitization, airway eosinophilia, goblet cell hyperplasia, and Th2 cell cytokine production. Furthermore, adoptive transfer of pDCs before sensitization prevented disease in a mouse asthma model. ${ }^{32}$ It was explained that pDCs did not induce T-cell division but suppressed the generation of effector $\mathrm{T}$ cells induced by mDCs. Moreover, LCs in the oral mucosa are mainly known to play a crucial role in initiating allergendependent immune responses. Hence, the oral mucosa represents a unique immunologic unit with the first contact with the allergen within the gastrointestinal tract, where immune tolerance is the natural outcome. Freshly isolated oral LCs expressed significantly higher amounts of major histocompatibility classes I and II, as well as costimulatory molecules CD40, CD80/B7.1, and CD86/ B7.2. Fc\&RI expression on oral LCs was further increased and correlated with the serum IgE levels in atopic individuals. Surprisingly, oral LCs constitutively expressed the high-affinity receptor for IgE (FceRI) even in nonatopic donors. ${ }^{33}$ As mentioned previously, the oral mucosa is an important site to induce immunologic tolerance to protein antigens. Dendritic LCs in both skin and oral epithelium are the first cells to encounter antigen; DCs derived from the oral mucosa were not able to transfer tolerance, but they acted as antigen-presenting cells in senso stricto irrespective of the source and route of antigen administration. ${ }^{34}$ It has been shown that regulatory T-cell clones induced by oral tolerance developed by oral administration of myelin basic protein can suppress autoimmune encephalomyelitis through peripheral tolerance, which was seen by production of transforming growth factor $\beta$ (TGF- $\beta$ ) with various amounts of IL- 4 and IL- $10 .{ }^{35}$ Further studies are required to elucidate the in vivo role of these cells and their subsets.

\section{SIT Induces Specific T-Cell Tolerance}

Induction of allergen-specific tolerance in peripheral $\mathrm{T}$ cells represents a key step in specific immunotherapy. ${ }^{36}$ The deviated immune response was characterized by suppressed proliferative T-cell and Th1 (interferon- $\gamma$ ) and Th2 (IL-5, IL-13) cytokine responses and increased IL10 and TGF- $\beta$ secretion by allergen-specific T cells. ${ }^{6,36,37}$ The $\mathrm{CD} 4{ }^{+} \mathrm{CD} 25^{+}$Treg cells, also called constitutive Treg cells, account for 5 to $10 \%$ of peripheral $\mathrm{CD} 4^{+} \mathrm{T}$ cells and inhibit the activation of effector $\mathrm{T}$ cells in the periphery. ${ }^{38,39} \mathrm{FOXP} 3$, the transcriptional regulator expressed on Treg cells, acts as a master switch gene for Treg cell development and function. ${ }^{38}$ Although the pathways regulating FOXP3 expression are yet unknown, a mechanism controlling Treg cell polarization, which is overruled by the Th2 differentiation pathway, was recently described. ${ }^{40}$ Increased IL-10 produced initially by activated inducible $\mathrm{CD} 4^{+} \mathrm{CD} 25^{+}$Treg cells and allergen-specific $\mathrm{T}$ cells and followed by B cells and monocytes by SIT causes specific tolerance in peripheral $\mathrm{T}$ cells and regulates specific IgE and IgG4 production toward normal IgG4related immunity. ${ }^{36}$

Neutralization of cytokine activity showed that T-cell suppression was induced by IL- 10 and TGF- $\beta$ during SIT and in normal immunity to the mucosal allergens. A deviation toward a regulatory or suppressor T-cell response during SIT and in normal immunity as a key event for the healthy immune response to mucosal antigens is present. ${ }^{37}$

\section{Regulation of B Cells and Specific Antibodies by SIT}

Induction of blocking antibodies, especially the IgG4 type, takes place in a successful SIT regimen. A substantial number of studies demonstrated increases in specific IgG4 levels together with clinical improvements. ${ }^{41,42}$ IgG4 is noninflammatory. IgG4 levels can reflect the dose of exposure and by itself, does not activate the complement. So far, no specific Fc receptors are defined. ${ }^{1}$ IgG4 captures the allergen before reaching the IgE bound effector cells, 
thus preventing the activation of mast cells and basophils. IgG4 has been shown to reduce the IgE-mediated degranulation of these cells in an allergen-specific manner, leading to a reduction in allergic inflammation. ${ }^{43-45}$ Blocking antibodies also inhibit IgE-facilitated allergen presentation to $\mathrm{T}$ cells and prevent allergen-induced boost of memory IgE production. ${ }^{1,6}$ On the other hand, IL-10 induced by specific immunotherapy suppresses IgE and synthesizes IgG4. In vitro studies demonstrate nonanaphylactogenic activity by blocking of IgE binding. IL-10 reduces release of proinflammatory cytokines by mast cells. The role of IL-10 in costimulatory pathways on B cells is by blocking B7/CD28. Also, IL-10 inhibits DC maturation and leads to reduced MHC class II and costimulatory ligand expression. Thus, IL-10 not only generates tolerance in T cells, it also regulates specific isotype formation. ${ }^{6}$ Moreover, TGF- $\beta$ suppresses IgE and is a class switch factor for IgA. IgA induced by Treg cells and Tr1 and Th3 cells is much less compared with Toll-like receptor (CpG+IL-2)-induced IgA in cell cultures. TGF- $\beta$ also downregulates FceRI expression on LCs. It upregulates the transcription factor FOXP3 and is associated with CTLA-4 expression in T cells. ${ }^{46}$

\section{Conclusion}

In a healthy immune response to noninfectious nonselfantigens, peripheral T-cell tolerance is the key immunologic mechanism. This tolerance induced by SIT includes suppression of $\mathrm{T}$ cells and switching of antibody profile into noninflammatory types IgG4 and IgA, with a decrease in IgE. Effector cells such as mast cells, eosinophils, and basophils are also suppressed, as well as late-phase reactions of allergic immune response. The proposed role of Treg cells and cytokines in SIT has been elucidated, and there is clear evidence to support IL-10 and/or TGF- $\beta$ secreting Treg cells and immunosuppressive cytokines as key players in mediating successful SIT and a healthy immune response to allergens.

\section{References}

1. Akdis M, Akdis CA. Mechanisms of allergen-specific immunotherapy. J Allergy Clin Immunol 2007;119:780-91.

2. Romagnani S. Immunologic influences on allergy and the TH1/ TH2 balance. J Allergy Clin Immunol 2004;113:395-400.

3. Larché M, Akdis CA, Valenta R. Immunological mechanisms of allergen-specific immunotherapy. Nat Rev Immunol 2006;6:76171.
4. Marcotte GV, Braun CM, Norman PS, et al. Effects of peptide therapy on ex vivo T cell responses. J Allergy Clin Immunol 1998; 101:506-13.

5. Lai L, Casale TB, Stokes J. Pediatric allergic rhinitis: treatment. Immunol Allergy Clin North Am 2005;25:283-99.

6. Jutel M, Akdis M, Blaser K, Akdis CA. Mechanisms of allergen specific immunotherapy-T-cell tolerance and more. Allergy 2006; 61:796-807.

7. Calderon MA, Alves B, Jacobson $\mathrm{M}$, et al. Allergen injection immunotherapy for seasonal allergic rhinitis. Cochrane Database Syst Rev 2007;(1):CD001936.

8. Frew AJ. How does sublingual immunotherapy work? J Allergy Clin Immunol 2007;120:533-6.

9. Wilson DR, Lima MT, Durham SR. Sublingual immunotherapy for allergic rhinitis: systematic review and meta-analysis. Allergy 2005;60:4-12.

10. Kussebi F, Karamloo F, Akdis M, et al. Advances in immunological treatment of allergy. Curr Med Chem 2003;2:297-308.

11. Bahceciler NN, Ozdemir C, Barlan IB. Immunologic aspects of sublingual immunotherapy in the treatment of allergy and asthma. Curr Med Chem 2007;14:265-9.

12. Bousquet J, Lockey R, Malling HJ, et al. Allergen immunotherapy: therapeutic vaccines for allergic diseases. World Health Organization. American Academy of Allergy, Asthma and Immunology. Ann Allergy Asthma Immunol 1998;81:401-5.

13. Durham SR, Walker SM, Varga EM, et al. Long-term clinical efficacy of grass pollen immunotherapy. N Engl J Med 1999;341: 468-75.

14. Ozdemir C, Yazi D, Gocmen I, et al. Efficacy of long-term sublingual immunotherapy as an adjunct to pharmacotherapy in house dust mite-allergic children with asthma. Pediatr Allergy Immunol 2007;18:508-15.

15. Larché M. Regulatory T cells in allergy and asthma. Chest 2007; 132:1007-14.

16. Bohle B, Kinaciyan T, Gerstmayr M, et al. Sublingual immunotherapy induces IL-10-producing $\mathrm{T}$ regulatory cells, allergenspecific T-cell tolerance, and immune deviation. J Allergy Clin Immunol 2007;120:707-13.

17. Larché M. Immunoregulation by targeting T cells in the treatment of allergy and asthma. Curr Opin Immunol 2006;18:745-50.

18. Hawrylowicz CM, O'Garra A. Potential role of IL-10-secreting regulatory T cells in allergy and asthma. Nat Rev Immunol 2005;5: 271-83.

19. Jutel M, Müller UR, Fricker M, et al. Influence of bee venom immunotherapy on degranulation and leukotriene generation in human blood basophils. Clin Exp Allergy 1996;26:1112-8.

20. Plewako H, Wosinska K, Arvidsson M, et al. Basophil interleukin 4 and interleukin 13 production is suppressed during the early phase of rush immunotherapy. Int Arch Allergy Immunol 2006;141:34653.

21. Eberlein-Konig B, Ullmann S, Thomas P, Przybilla B. Tryptase and histamine release due to a sting challenge in bee venom allergic patients treated successfully or unsuccessfully with hyposensitization. Clin Exp Allergy 1995;25:704-12.

22. Plewako H, Arvidsson M, Oancea I, et al. The effect of specific immunotherapy on the expression of costimulatory molecules in late phase reaction of the skin in allergic patients. Clin Exp Allergy 2004;34:1862-7. 
23. Varney VA, Hamid QA, Gaga M, et al. Influence of grass pollen immunotherapy on cellular infiltration and cytokine mRNA expression during allergen-induced late-phase cutaneous responses. J Clin Invest 1993;92:644-51.

24. Durham SR, Ying S, Varney VA, et al. Grass pollen immunotherapy inhibits allergen-induced infiltration of CD4+ T lymphocytes and eosinophils in the nasal mucosa and increases the number of cells expressing messenger RNA for interferon- $\gamma$. J Allergy Clin Immunol 1996;97:1356-65.

25. Wilson DR, Irani AM, Walker SM, et al. Grass pollen immunotherapy inhibits seasonal increases in basophils and eosinophils in the nasal epithelium. Clin Exp Allergy 2001;31: 1705-13.

26. Rak S, Heinrich C, Jacobsen L, et al. A double-blinded, comparative study of the effects of short preseason specific immunotherapy and topical steroids in patients with allergic rhinoconjunctivitis and asthma. J Allergy Clin Immunol 2001;108: 921-8.

27. Durham SR, Varney MA, Gaga M, et al. Grass pollen immunotherapy decreases the number of mast cells in the skin. Clin Exp Allergy 1999;29:1490-6.

28. Shim JY, Kim BS, Cho SH, et al. Allergen-specific conventional immunotherapy decreases immunoglobulin E mediated basophil histamine releasability. Clin Exp Allergy 2003;33:52-7.

29. Marogna M, Spadolini I, Massolo A, et al, J Allergy Clin Immunol 2005;115:1184-8.

30. Vermaelen KY, Carro-Muino I, Lambrecht BN, Pauwels RA. Specific migratory dendritic cells rapidly transport antigen from the airways to the thoracic lymph nodes. J Exp Med 2001;193:5160.

31. Jonuleit H, Schmitt E, Schuler G, et al. Induction of interleukin 10producing, nonproliferating $\mathrm{CD} 4+\mathrm{T}$ cells with regulatory properties by repetitive stimulation with allogeneic immature human dendritic cells. J Exp Med 2000;192:1213-22.

32. De Heer HJ, Hammad H, Soullié T, et al. Essential role of lung plasmacytoid dendritic cells in preventing asthmatic reactions to harmless inhaled antigen. J Exp Med 2004;200:89-98.

33. Allam JP, Novak N, Fuchs C, et al. Characterization of dendritic cells from human oral mucosa: a new Langerhans' cell type with high constitutive FcepsilonRI expression. J Allergy Clin Immunol 2003;112:141-8.
34. Van Wilsem EJ, Van Hoogstraten IM, Brevé J, et al. Dendritic cells of the oral mucosa and the induction of oral tolerance. A local affair. Immunology 1994;83:128-32.

35. Chen Y, Kuchroo VK, Inobe J, et al. Regulatory $\mathrm{T}$ cell clones induced by oral tolerance: suppression of autoimmune encephalomyelitis. Science 1994;265:1237-40.

36. Akdis CA, Blesken T, Akdis $\mathrm{M}$, et al. Role of interleukin 10 in specific immunotherapy. J Clin Invest 1998;102:98-106.

37. Jutel M, Akdis M, Budak F, et al. IL-10 and TGF-beta cooperate in the regulatory $\mathrm{T}$ cell response to mucosal allergens in normal immunity and specific immunotherapy. Eur J Immunol 2003;33: $1205-14$

38. Sakaguchi S, Sakaguchi N, Asano M, et al. Immunologic selftolerance maintained by activated $\mathrm{T}$ cells expressing IL-2 receptor alpha-chains (CD25). Breakdown of a single mechanism of selftolerance causes various autoimmune diseases. J Immunol 1995; 155:1151-64.

39. Akdis M. Healthy immune response to allergens: T regulatory cells and more. Curr Opin Immunol 2006;18:738-44.

40. Mantel PY, Kuipers H, Boyman O, et al. GATA3-driven Th2 responses inhibit TGF-betal-induced FOXP3 expression and the formation of regulatory T cells. PLoS Biol 2007;5(12):e329.

41. Flicker S, Valenta R. Renaissance of the blocking antibody concept in type I allergy. Int Arch Allergy Immunol 2003;132:13-24.

42. Wachholz PA, Durham SR. Mechanisms of immunotherapy: IgG revisited. Curr Opin Allergy Clin Immunol 2004;4:313-8.

43. Mothes N, Heinzkill M, Drachenberg KJ, et al. Allergen-specific immunotherapy with a monophosphoryl lipid A-adjuvanted vaccine: reduced seasonally boosted immunoglobulin E production and inhibition of basophil histamine release by therapy-induced blocking antibodies. Clin Exp Allergy 2003;33:1198-208.

44. Visco V, Dolecek V, Denepoux S, et al. Human IgG monoclonal antibodies that modulate the binding of specific IgE to birch pollen Bet v 1. J Immunol 1996;157:956-62.

45. Flicker S, Steinberger P, Norderhaug L, et al. Conversion of grass pollen allergen specific human IgE into a protective IgG1 antibody. Eur J Immunol 2002;32:2156-62.

46. Chen W, Jin W, Hardegen N, et al. Conversion of peripheral CD4+CD25- naive $\mathrm{T}$ cells to $\mathrm{CD} 4+\mathrm{CD} 25+$ regulatory $\mathrm{T}$ cells by TGF-b induction of transcription factor Foxp3. J Exp Med 2003; 198:1875-86 